\title{
Efek Corporate Social Responsibility pada Brand Equity Dimediasi Corporate Image dan Brand Awareness
}

\author{
Rulloh Delia Anggorawati ${ }^{1}$, Budiyanto ${ }^{2}$, Esti Margiyanti Utami ${ }^{3}$
}

Program Studi Manajemen, Universitas Muhammadiyah Purworejo ${ }^{1,2,3}$

Email korespondensi: budiyanto@umpwr.ac.id ${ }^{2}$, $\underline{\text { estiutami@umpwr.ac.id }}^{3}$

Received: 11 Jan 2021 Reviewed: 2 Feb 2021 Accepted: 19 Mar 2021 Published: 30 Apr 2021

\begin{abstract}
The purpose of this study examine the influence of corporate social responsibility on brand equity; the effect of corporate social responsibility on brand awareness; the influence of corporate social responsibility on corporate image; the influence of brand awareness on brand equity; the effect of corporate image on brand equity; effect of corporate social responsibility on brand equity mediated by brand awareness; effect of corporate social responsibility on brand equity mediated by corporate image. Sample of this research is 120 people. Sampling technique used in this study is judgment sampling. Hypothesis testing used hierarchical regression analysis. The results showed that corporate social responsibility has an positive effect on brand equity, corporate social responsibility has a positive effect on brand awareness, corporate social responsibility has a positive effect on corporate image, brand awareness has a positive effect on brand equity, corporate image has a positive effect on brand equity, brand awareness mediates the effect of corporate social responsibility on brand equity, and corporate image mediates the influence of corporate social responsibility on brand equity.
\end{abstract}

Keywords: corporate social responsibility, brand awareness, corporate image, brand equity

\begin{abstract}
ABSTRAK
Penelitian ini bertujuan untuk menguji pengaruh corporate social responsibility terhadap brand equity; pengaruh corporate social responsibility terhadap brand awareness; pengaruh corporate social responsibility terhadap corporate image; pengaruh brand awareness terhadap brand equity; pengaruh corporate image terhadap brand equity; pengaruh corporate social responsibility terhadap brand equity yang dimediasi oleh brand awareness; pengaruh corporate social responsibility terhadap brand equity yang dimediasi oleh corporate image. Sampel penelitian ini berjumlah 120 orang. Teknik sampling yang digunakan dalam penelitian ini yaitu judgement sampling. Pengujian hipotesis yang digunakan adalah hierarchical regression analysis. Hasil penelitian menunjukkan bahwa corporate social responsibility berpengaruh positif terhadap brand equity, corporate social responsibility berpengaruh positif terhadap brand awareness, corporate social responsibility berpengaruh positif terhadap corporate image, brand awareness berpengaruh positif terhadap brand equity, corporate image berpengaruh positif terhadap brand equity, brand awareness memediasi pengaruh corporate social responsibility terhadap brand equity, dan corporate image memediasi pengaruh corporate social responsibility terhadap brand equity.
\end{abstract}

Kata kunci: corporate social responsibility, brand awareness, corporate image, brand equity 


\section{A. PENDAHULUAN}

Sebuah perusahaan yang bergerak di bidang jasa perbankan memerlukan suatu efisiensi dengan mempersingkat serta mempercepat akses layanan yang merupakan kebutuhan nasabah. Diharapkan hal ini dapat mendukung peran perusahaan perbankan dalam membentuk suatu ekuitas merek yang baik terhadap produk jasanya. Fenomena persaingan di era globalisasi semakin mengarahkan sistem perekonomian suatu negara ke mekanisme pasar bebas di mana semua pelaku usaha saling berkompetisi yang berdampak pada pemasar dalam memposisikan usahanya untuk selalu mengembangkan dan merebut pangsa pasar.

Aaker (1991) mengatakan brand equity sebagai seperangkat aset dan liabilitas merek yang dikaitkan dengan suatu merek, nama, dan simbol yang menambah atau mengurangi nilai yang diberikan oleh suatu produk atau layanan kepada perusahaan atau kepada pelanggan perusahaan. Di sisi lain, Keller (1993) mengukur brand equity berbasis pelanggan dengan memfokuskan hanya komponen persepsi. Keller (1993) mengusulkan dua komponen persepsi yaitu kesadaran merek dan asosiasi merek.

Kesadaran merek (brand awareness) dapat didefinisikan sebagai kemampuan potensial pembeli untuk mengenali atau mengingat bahwa suatu merek adalah anggota dari kategori produk tertentu (Aaker,1991). Brand awareness menurut Shimp (2014), adalah sebuah persoalan mengenai apakah nama sebuah merek muncul dalam pikiran ketika konsumen berpikir mengenai suatu kategori produk tertentu. Brand awareness dan corporate image sangat penting ketika perusahaan menargetkan pasar baru atau menawarkan produk baru (Jalleh et al., 2002). Dalam situasi tersebut, peran corporate image sangatlah mempengaruhi keberhasilan kegiatan suatu perusahaan (Sofyani \& Hurriyati, 2010).

Smith \& Taylor (2004) menjelaskan secara khusus tentang corporate image yaitu persepsi orang tentang suatu organisasi, citra dan persepsi diciptakan melalui semua indera, penglihatan, suara, bau, sentuhan, rasa, dan perasaan yang dialami melalui penggunaan produk, layanan pelanggan, lingkungan komersial, dan komunikasi perusahaan. Fombrun (2005) mengakui bahwa meningkatkan citra perusahaan adalah motivasi ekstrinsik bagi perusahaan untuk terlibat dalam lebih banyak kegiatan corporate social responsibility (CSR).

Konsep CSR telah muncul pada awal 1950-an karena meningkatnya peran strategis kontribusi perusahaan terhadap kesejahteraan jangka panjang masyarakat dan pelanggan (Carroll, 1999). Menurut Kotler dan Lee (2005) CSR adalah komitmen untuk meningkatkan kesejahteraan masyarakat melalui praktik bisnis yang bebas dan kontribusi sumber daya perusahaan. Jones (1980), menambahkan bahwa CSR adalah gagasan bahwa perusahaan memiliki kewajiban kepada kelompok-kelompok pendukung dalam masyarakat selain 
pemegang saham dan di luar yang ditentukan oleh undang-undang dan kontrak serikat pekerja. Ketika individu menyadari inisiatif CSR perusahaan, mereka menunjukkan sikap yang lebih positif terhadap produk dan layanan perusahaan dibandingkan dengan individu yang tidak mengetahui inisiatif CSR (Luo \& Bhattacharya, 2006; Sen \& Bhattacharya, 2001; Klein \& Dawar, 2004; Bhattacharya, Sen, \& Korschun, 2007). Dalam penelitian Hafez (2018) menyatakan bahwa CSR memiliki pengaruh langsung yang signifikan terhadap corporate image, brand awareness, dan brand equity. Hasil dari penelitian itu mengonfirmasi bahwa corporate image dan brand awareness sebagian memediasi hubungan antara CSR dan brand equity.

Salah satu perusahaan yang telah menjalankan program CSR yaitu PT Bank Rakyat Indonesia (Persero) Tbk atau Bank BRI. Bank BRI merupakan bank milik pemerintah yang terbesar dan tersebar di Indonesia. Berdiri sejak tahun 1895 hingga saat ini Bank BRI memiliki peran penting dalam menggerakkan roda perekonomian nasional. Sebagai Badan Usaha Milik Negara (BUMN), Bank BRI turut melaksanakan program tanggung jawab sosial atau corporate social responsibility (CSR), terutama melalui pelaksanaan Program Bina Lingkungan yang dikenal dengan nama BRI Peduli (Bank Rakyat Indonesia, "BRI Peduli Tentang Kami").

BRI Peduli memiliki konsep untuk membantu meningkatkan kondisi lingkungan (Pro Planet), masyarakat (Pro People), dan ekonomi (Pro Profit). Bank BRI memiliki komitmen kuat dalam menjalankan BRI Peduli dengan mengusung tema "Bangga Berindonesia" sebagai tagline dari program-program CSR dan Bina Lingkungan. Bank BRI berkomitmen menjadikan BRI Peduli sebagai kegiatan yang memberikan dampak positif bagi masyarakat. BRI Peduli terbagi dalam 7 (tujuh) sektor bantuan yaitu: 1) sektor bantuan untuk korban bencana alam yang dikomunikasikan dengan nama Indonesia Peduli; 2) sektor bantuan pendidikan, dapat berupa pelatihan, prasarana dan sarana pendidikan yang dikomunikasikan dengan nama Indonesia Cerdas; 3) sektor peningkatan kesehatan yang dikomunikasikan dengan nama Indonesia Sehat; 4) sektor pengembangan prasarana dan/atau sarana umum yang dikomunikasikan dengan nama Indonesia Membangun; 5) sektor sarana ibadah yang dikomunikasikan dengan nama Indonesia Takwa; 6) sektor pelestarian alam, yang dikomunikasikan dengan nama Indonesia Lestari; 7) bantuan sosial kemasyarakatan dalam rangka pengentasan kemiskinan, yang dikomunikasikan dengan nama Indonesia Sejahtera.

Dari berbagai komitmen yang telah dilaksanakan Bank BRI di bidang CSR dan Bina Lingkungan, Bank BRI terus meningkatkan kualitas Program CSR dan Bina Lingkungan dengan membangun sistem manajemen program, baik perencanaan, pelaksanaan monitoring 
dan evaluasi, termasuk pengukuran dampak program serta kesesuaian dengan peraturan yang berlaku. Kini BRI Peduli menjadi pelopor dan merupakan bank terbaik dalam pelaksanaan Program CSR dan Bina Lingkungan selama 2 tahun berturut-turut yaitu tahun 2018 dan 2019 sebagai Best Bank For CSR in Indonesia dalam ajang Asia Money Best Bank Award (Bank Rakyat Indonesia, "BRI Peduli Tentang Kami"). Hal ini sesuai dengan pendapat Hafez (2018) yang menyatakan bahwa CSR memiliki pengaruh langsung yang signifikan terhadap corporate image, brand awareness, dan brand equity. Hasil dari penelitian itu mengonfirmasi bahwa corporate image dan brand awareness sebagian memediasi hubungan antara CSR dan brand equity.

\section{B. TELAAH PUSTAKA}

\section{Brand Equity}

Aaker (1991) mendefinisikan brand equity sebagai seperangkat aset dan liabilitas merek yang dikaitkan dengan suatu merek, nama, dan simbol yang menambah atau mengurangi nilai yang diberikan oleh suatu produk atau layanan kepada perusahaan dan/atau kepada pelanggan perusahaan itu. Aaker (1991) mengusulkan konsep brand equity bahwa ekuitas merek menciptakan nilai bagi pelanggan dan perusahaan, nilai bagi pelanggan meningkatkan nilai bagi perusahaan, dan ekuitas merek terdiri dari beberapa dimensi. Yoo et al. (2000) memperluas model Aaker dengan dua cara. Pertama, menempatkan konstruksi terpisah, ekuitas merek, antara dimensi ekuitas merek dan nilai bagi pelanggan dan perusahaan. Konstruk ekuitas merek menunjukkan bagaimana dimensi individu terkait dengan ekuitas merek. Karena ekuitas merek adalah nilai sebuah nama merek, sebuah konstruksi bisa tinggi atau rendah. Menetapkan konstruksi ekuitas merek yang terpisah akan membantu kita memahami bagaimana dimensi berkontribusi pada ekuitas merek. Kedua, anteseden ekuitas merek, yaitu aktivitas pemasaran dengan asumsi bahwa hal tersebut memiliki pengaruh yang signifikan terhadap dimensi ekuitas merek (Yoo et al., 2000). Brand equity mengacu pada utilitas tambahan atau nilai total yang ditambahkan ke produk berdasarkan nama mereknya (Yoo \& Donthu, 2001).

\section{Corporate Social Responsibility}

Konsep Corporate Social Responsibility (CSR) telah muncul pada awal 1950an karena meningkatnya peran strategis kontribusi perusahaan terhadap kesejahteraan jangka panjang masyarakat dan pelanggan (Carroll, 1999). Seiring berjalannya waktu, definisi CSR dan praktik-praktiknya meluas luar biasa. Menurut Kotler \& Lee (2005) CSR adalah komitmen untuk meningkatkan kesejahteraan masyarakat melalui praktik bisnis yang bebas dan 
kontribusi sumber daya perusahaan. CSR mengacu pada kegiatan perusahaan sehubungan dengan kewajiban sosial yang dirasakannya (Brown \& Dacin, 1997).

Menurut The World Business Council for Sustainable Development, CSR adalah komitmen perusahaan secara terus-menerus untuk bertindak secara etis dan berkontribusi bagi pengembangan ekonomi yang meningkatkan kualitas hidup karyawan dan keluarganya, sekaligus juga peningkatan kualitas komunitas lokal dan masyarakat secara lebih luas. Lantos (2001) juga menambahkan bahwa kegiatan CSR perusahaan dirancang untuk membawa eksposur bagi perusahaan, meningkatkan reputasi perusahaan dan citra merek yang mencerminkan keuntungan secara positif.

\section{Brand Awareness}

Menurut Aaker (1991), brand awareness adalah kemampuan potensial pembeli untuk mengenali atau mengingat bahwa suatu merek adalah anggota dari kategori produk tertentu. Di sisi lain menurut Keller (2013), brand awareness berkaitan dengan kekuatan suatu merek di dalam benak yang dapat kita ukur sebagai kemampuan konsumen untuk mengidentifikasi merek di bawah kondisi yang berbeda. Kesadaran merek menunjukkan kesanggupan konsumen (calon pembeli) dalam mengingat kembali (recognize) atau mengenali (recall) bahwa suatu merek merupakan suatu bagian dari kategori produk tertentu (Durianto et al., 2001).

\section{Corporate Image}

Smith \& Taylor (2004) menjelaskan secara khusus tentang corporate image yaitu persepsi orang tentang suatu organisasi, citra dan persepsi diciptakan melalui semua indera; penglihatan, suara, bau, sentuhan, rasa, dan perasaan yang dialami melalui penggunaan produk, layanan pelanggan, lingkungan komersial dan komunikasi perusahaan. Ini adalah hasil langsung dari semua yang dilakukan perusahaan (atau tidak dilakukan). Kemudian menurut Jefkins (1996) tentang pentingnya citra bagi perusahaan menyebutkan bahwa sangat penting untuk memiliki karakter yang baik dan reputasi yang baik seperti itu untuk seorang pebisnis individu dan untuk alasan yang persis sama, nama perusahaan sangat berkaitan dengan keputusan pembelian konsumen.

Nguyen \& Leblanc (2001) menyatakan corporate image berhubungan dengan fisik dan atribut yang berhubungan dengan perusahaan seperti nama, bangunan, produk atau jasa untuk memengaruhi kualitas yang dikomunikasikan oleh setiap orang supaya tertarik dengan perusahaan. Citra menggambarkan keseluruhan kesan yang dibuat publik tentang perusahaan dan produknya. 


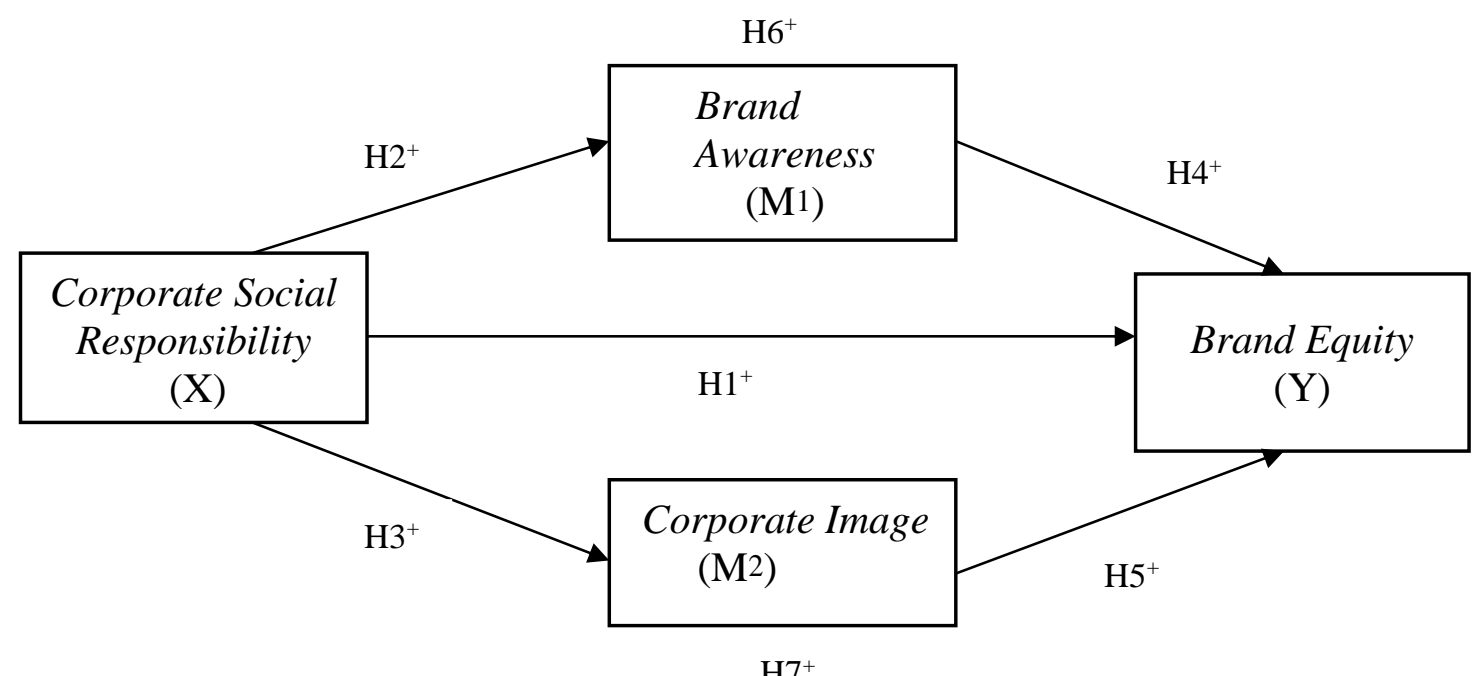

$\mathrm{H} 7^{+}$

Gambar 1. Kerangka Penelitian

\section{Pengembangan Hipotesis}

\section{Pengaruh Corporate Social Responsibility terhadap Brand Equity}

Hoeffler \& Keller (2002) menyatakan bahwa program pemasaran sosial perusahaan dapat menciptakan brand equity dengan membangun kesadaran merek, citra merek, kredibilitas merek, perasaan merek, keterlibatan merek, dan menciptakan komunitas merek. Hasil penelitian Hafez (2018); Lai et al. (2010); Wang (2010); Hur, et al. (2013) diperoleh hasil bahwa program CSR berpengaruh positif yang signifikan terhadap brand equity.

$\mathrm{H}_{1}$ : Corporate social responsibility berpengaruh positif terhadap brand equity.

\section{Pengaruh Corporate Social Responsibility terhadap Brand Awareness}

Aaker (1991), brand awareness didefinisikan sebagai kemampuan potensial pembeli untuk mengenali dan mengingat bahwa suatu merek adalah anggota dari kategori produk tertentu. Kotler (2008) menyatakan bahwa ketika suatu organisasi sepenuhnya terlibat dalam kegiatan CSR akan menciptakan kesadaran pelanggan yang kuat mengenai merek perusahaan. Hasil penelitian Hafez (2018); Bankas (2010); Bhattacharya dan Sen (2004), diperoleh hasil bahwa program CSR berpengaruh positif dan signifikan terhadap brand awareness.

$\mathrm{H}_{2}$ : Corporate social responsibility berpengaruh positif terhadap brand awareness.

\section{Pengaruh Corporate Social Responsibility terhadap Corporate Image}

Menurut Keller (1993), persepsi positif perusahaan oleh pelanggan dikenal sebagai corporate image. Jadi, CSR adalah gabungan persepsi para pemangku kepentingan terhadap organisasi (Abratt \& Kleyn, 2012). Selain itu, perusahaan dengan citra buruk di pasar dapat secara efektif berubah menjadi citra yang baik melalui program CSR karena persepsi orang positif terhadap perusahaan yang bertanggung jawab secara sosial (Yoon et al., 2006; Mitra, 
2011). Hasil penelitian Hafez (2018); Branco \& Rodrigues (2006); Fatma et al. (2015); Lai et al. (2010) diperoleh hasil bahwa program CSR memiliki efek positif yang signifikan terhadap corporate image.

$\mathrm{H}_{3}$ : Corporate social responsibility berpengaruh positif terhadap corporate image.

\section{Pengaruh Brand Awareness terhadap Brand Equity}

Kesadaran merek adalah bagaimana konsumen mengasosiasikan merek dengan produk tertentu yang ingin mereka miliki. Kesadaran merek sangat diperlukan agar proses komunikasi muncul, yaitu kesadaran top-of-the-mind (Macdonald \& Sharp, 2003; Netemeyer et al., 2004). Hasil penelitian Wilcox et al. (2008) dan Pouromid \& Iranzadeh (2012) diperoleh hasil bahwa brand awareness memiliki efek positif yang signifikan terhadap brand equity.

$\mathrm{H}_{4}$ : Brand awareness berpengaruh positif terhadap brand equity

\section{Pengaruh Corporate Image terhadap Brand Equity}

Corporate image yang baik membedakan perusahaan dari pesaingnya. Dengan demikian hal ini merupakan aset strategis yang penting bagi perusahaan bukan hanya karena potensi penciptaan nilainya, tetapi juga karena karakternya yang tidak berwujud mempersulit perusahaan pesaing untuk mereplikasi (Fombrun \& Shanley, 1990; Roberts \& Dowling, 2002). Hasil penelitian Lai et al. (2010) dan Handayani (2012) diperoleh hasil bahwa corporate image memiliki efek positif yang signifikan terhadap brand equity.

$\mathrm{H}_{5}$ : Corporate image berpengaruh positif terhadap brand equity.

\section{Pengaruh Corporate Social Responsibility terhadap Brand Equity dimediasi Brand}

\section{Awareness}

Menurut Keller (2013), tingkat kesadaran merek yang tinggi dan keakraban merek, serta asosiasi merek yang kuat dalam memori dapat menciptakan brand equity berbasis pelanggan. Brand equity memiliki peran penting dalam proses pengambilan keputusan konsumen. Ketika individu menyadari inisiatif CSR perusahaan, mereka menunjukkan sikap yang lebih positif terhadap produk dan layanan perusahaan dibandingkan dengan individu yang tidak mengetahui inisiatif CSR (Luo \& Bhattacharya, 2006; Sen \& Bhattacharya, 2001; Klein \& Dawar, 2004; Bhattacharya et al., 2007). Hasil penelitian Hafez (2018); Singh \& Verma (2017); Alhaddad (2015) diperoleh hasil bahwa brand awareness mampu memediasi pengaruh CSR terhadap brand equity.

$\mathrm{H}_{6}$ : Corporate social responsibility berpengaruh positif terhadap brand equity dimediasi brand awareness. 
Pengaruh Corporate Social Responsibility terhadap Brand Equity dimediasi Corporate Image

Menurut Jones (2005), pasar global yang sangat kompetitif, organisasi terus menggunakan CSR sebagai alat taktis untuk menanggapi harapan berbagai pemangku kepentingan seperti opini publik, media, organisasi non pemerintah, dan pelanggan. SCR digunakan untuk membangun citra perusahaan yang menguntungkan yang pada gilirannya menciptakan brand equity untuk perusahaan. Hasil penelitian Hafez (2018); McWilliams, Siegel, \& Wright, (2006); (Arendt \& Brettel, 2010); Vazifehdust et al. (2014); Kim \& Hyun (2011) diperoleh hasil bahwa corporate image mampu memediasi pengaruh CSR terhadap brand equity.

$\mathrm{H}_{7}$ : Corporate social responsibility berpengaruh positif terhadap brand equity dimediasi oleh corporate image.

\section{METODE PENELITIAN}

\section{Populasi dan Teknik Sampling}

Penelitian yang dilakukan termasuk penelitian kuantitatif, karena data yang diperoleh berupa angka yang berasal dari kuesioner. Sedangkan pendekatan penelitian ini termasuk ke dalam penelitian survei (survey) atau lengkapnya self-administrated survey, yaitu metode pengumpulan data primer dengan memberikan pernyataan-pernyataan kepada responden (Hartono,2013). Populasi pada penelitian ini adalah semua nasabah PT Bank Rakyat Indonesia (Persero) Cabang Purworejo. Selanjutnya, sampel dalam penelitian ini sebanyak 120 orang yang ditentukan dengan teknik non probability sampling. Teknik sampling yang digunakan dalam penelitian ini yaitu judgement sampling. Judgement sampling adalah salah satu teknik sampling di mana peneliti memilih sampel berdasarkan penilaian terhadap beberapa karakteristik anggota sampel yang disesuaikan dengan maksud penelitian (Kuncoro, 2013). Kriteria respondennya adalah nasabah PT Bank Rakyat Indonesia (Persero) Cabang Purworejo yang berdomisili di Purworejo. Konsumen yang berusia minimal 18 tahun. Menurut Kasali (2007) kriteria responden berusia minimal 18 tahun diasumsikan responden dapat memberikan data yang akurat dan dapat dipertanggungjawabkan.

\section{Definisi Operasional Variabel}

\section{Brand Equity}

Menurut Aaker (1991), brand equity merupakan serangkaian aset dan kewajiban (liabilities) merek yang terkait dengan sebuah merek, nama, dan simbolnya, yang menambah atau mengurangi nilai yang diberikan sebuah produk atau jasa kepada perusahaan dan/atau 
konsumen perusahaan tersebut. Menurut Yoo et al. (2000), indikator-indikator yang digunakan untuk mengukur brand equity, yaitu: 1) sangat tepat untuk membeli produk merek $\mathrm{X}$ guna menggantikan merek lainnya, meskipun kelihatannya serupa; 2) bahkan jika merek lain memiliki fitur seperti merek X, saya akan tetap membeli merek X; 3) jika ada produk merek lain sebagus merek X, saya lebih memilih membeli merek X; 4) jika merek lain tidak berbeda dari merek X, tampaknya lebih baik membeli merek X

\section{Corporate Social Responsibility}

Menurut Kotler \& Lee (2005) corporate social responsibility adalah komitmen untuk meningkatkan kesejahteraan masyarakat melalui praktik bisnis yang bebas dan kontribusi sumber daya perusahaan. Menurut Berens, Cees, Garrit, (2005), indikator-indikator yang digunakan untuk mengukur CSR, yaitu: 1) bertanggung jawab sosial; 2) bertanggung jawab untuk kesejahteraan masyarakat; 3) bertanggung jawab secara lingkungan.

\section{Brand Awareness}

Menurut Aaker (1991), brand awareness adalah kemampuan potensial pembeli untuk mengenali atau mengingat bahwa suatu merek adalah anggota dari kategori produk tertentu. Menurut Yoo et al. (2000), indikator-indikator yang digunakan untuk mengukur brand awareness,yaitu: 1) dapat menyadari merek; 2) dapat mengenali merek; 3) dapat mengingat logo/simbol merek; 4) tingkat pengetahuan terhadap merek.

\section{Corporate Image}

Menurut Smith \& Taylor (2004), corporate image yaitu persepsi orang tentang suatu organisasi, citra dan persepsi diciptakan melalui semua indera; penglihatan, suara, bau, sentuhan, rasa, dan perasaan yang dialami melalui penggunaan produk, layanan pelanggan, lingkungan komersial, dan komunikasi perusahaan. Menurut Nguyen \& Leblanc (2001), indikator-indikator yang digunakan untuk mengukur corporate image, yaitu: 1) kesan perusahaan; 2) reputasi; 3) akses layanan; 4) penawaran layanan

\section{Pengujian Instrumen Uji}

Untuk melakukan pengujian hipotesis penelitian ini menggunakan hierarchical regression analysis, peneliti mengacu pada penjelasan Baron \& Kenny (1986). Menurut Baron \& Kenny (1986) dalam suatu variabel disebut mediator jika variabel tersebut ikut memengaruhi hubungan antara variabel indepeden pada variabel dependen. Analisis ini bertujuan untuk menguji pengaruh corporate social responsibility $(\mathrm{X})$ terhadap brand equity (Y) melalui brand awareness $\left(\mathrm{M}_{1}\right)$ corporate image $\left(\mathrm{M}_{2}\right)$. Asumsi-asumsi yang mendasari model Baron \& Kenny (1986) sebagai berikut: 1) hubungan X dan Y (jalur c) harus signifikan; 2) Hubungan $X$ dan $M$ (jalur a) harus signifikan; 3) hubungan $M$ dan $Y$ (jalur b) harus 
signifikan. Pengaruh pemediasi penuh (full mediated) terjadi apabila pengaruh variabel independent $(\mathrm{X})$ terhadap variabel dependent $(\mathrm{Y})$ yang semula signifikan menjadi tidak signifikan ketika variabel mediasi (M) diregresikan secara bersama-sama. Pengaruh pemediasi sebagian (partially mediated) terjadi apabila pengaruh variabel independent $(\mathrm{X})$ terhadap variabel dependent $(\mathrm{Y})$ yang signifikansinya terjadi peningkatan atau penurunan ketika variabel mediasi (M) diregresikan secara bersama-sama.

Uji validitas diukur dengan menggunakan Pearson Correlation. Jika korelasi faktor sebesar $>0,3$ ke atas, maka instrumen memiliki validitas yang baik. Uji reliabilitas diukur dengan menggunakan Cronbach Alpha. Jika nilai a (Alpha Cronbach) > 0,7 maka item variabel tersebut dinyatakan reliabel.

\section{HASIL DAN PEMBAHASAN}

Hasil analisis data pengaruh corporate social responsibility terhadap brand equity yang dimediasi oleh brand awareness dan corporate image dengan menggunakan SPSS 24.0 dapat ditunjukan dalam Gambar 2.

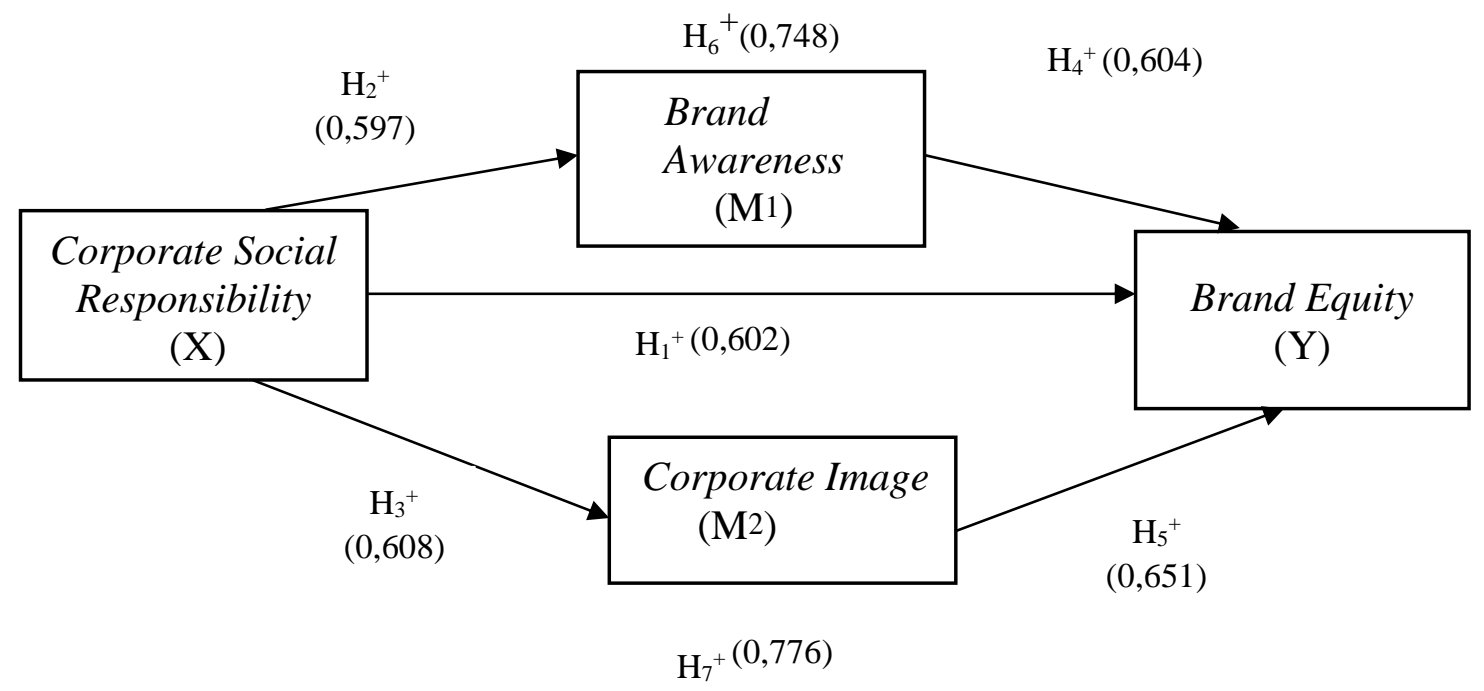

Gambar 2. Hasil Analisis Data

\section{Langkah 1}

Langkah 1 bertujuan untuk membuktikan hipotesis kesatu $\left(\mathrm{H}_{1}\right.$ : corporate social responsibility berpengaruh positif terhadap brand equity). Hasil analisis regresi langkah 1 dapat dilihat pada tabel 1 .

Tabel 1. Hasil Analisis Regresi Langkah 1

\begin{tabular}{cccc}
\hline Model & Beta & Nilai Signifikansi & Keterangan \\
\hline$X \rightarrow Y$ & 0,602 & 0,000 & Positif dan signifikan \\
\hline
\end{tabular}

Sumber : Data primer diolah, 2021 
Berdasarkan tabel 1, hasil analisis regresi pengaruh corporate social responsibility $(\mathrm{X})$ terhadap brand equity (Y) menghasilkan nilai koefisien regresi (b) corporate social responsibility (X) terhadap brand equity (Y) sebesar 0,602 dengan nilai signifikansi 0,000 $\left(p_{\text {value }}<0,05\right)$. Sehingga diperoleh persamaan garis regresi $\mathrm{X}=0,602 \mathrm{Y}$. Hal ini menunjukkan bahwa hipotesis kesatu $\left(\mathrm{H}_{1}\right)$ yang diajukan dalam penelitian yaitu corporate social responsibility berpengaruh positif terhadap brand equity diterima.

Diterimanya hipotesis kesatu $\mathrm{H}_{1}$ dalam penelitian ini karena PT Bank BRI (Persero) mempertahankan program-program corporate social responsibility (CSR) yang dikelola dengan baik untuk mencapai networking calon nasabah PT Bank BRI (Persero). PT Bank BRI (Persero) secara nyata telah berhasil melaksanakan program CSR yang bertanggung jawab sosial dan lingkungan dengan Program Bina Lingkungan yang dikenal dengan nama BRI Peduli. PT Bank BRI (Persero) berkomitmen menjadikan BRI Peduli sebagai kegiatan yang memberikan dampak positif bagi masyarakat.

BRI Peduli terbagi dalam 7 (tujuh) sektor bantuan, yaitu bantuan korban bencana alam, bantuan pendidikan (dapat berupa pelatihan prasarana dan sarana pendidikan), bantuan peningkatan kesehatan, bantuan pengembangan prasarana dan/atau sarana umum, bantuan sarana ibadah, bantuan pelestarian alam, dan bantuan sosial kemasyarakatan dalam rangka pengentasan kemiskinan. Semakin banyak keterlibatan PT Bank BRI (Persero) dalam melaksanakan program CSR semakin PT Bank BRI (Persero) dapat memengaruhi persepsi kualitas nasabahnya untuk menggunakan produk dan jasa keuangannya.

PT Bank BRI (Persero) juga merambah layanan perbankan kepada pengusaha kecil yang berada di dalam pasar-pasar tradisional. Melalui Teras BRI yang diluncurkan sejak akhir tahun 2009, unit kerja mikro ini diharapkan mampu menjangkau pedagang di pasar tradisional yang sebelumnya belum tersentuh layanan perbankan secara optimal. Sebagai bank yang beroperasi di tengah populasi masyarakat terbesar keempat di dunia, PT Bank BRI (Persero) berupaya tetap menjadi partner utama bagi masyarakat Indonesia di dalam mengembangkan perekonomiannya.

Kekuatan yang dimiliki PT Bank BRI (Persero) inilah yang mampu menciptakan loyalitas merek nasabah terhadap PT Bank BRI (Persero) diantara jasa keuangan bank pesaing lainnya. Program yang dijalankan oleh PT Bank BRI (Persero) dapat menambah nilai dari brand equity; seperti persepsi kualitas produk dan jasa keuangan, peningkatan awareness, pengalaman, sekaligus loyalitas nasabah karena dapat dirasakan nasabah secara langsung. Dapat disimpulkan dengan program yang ditawarkan memotivasi nasabah dalam 
menggunakan jasa layanan keuangan PT Bank BRI (Persero) yang dapat meningkatkan brand equity di masa mendatang sejalan dengan perbaikan kualitas kehidupan masyarakat Indonesia.

\section{Langkah 2}

Langkah 2 bertujuan untuk membuktikan hipotesis kedua $\left(\mathrm{H}_{2}\right.$ : corporate social responsibility berpengaruh positif terhadap brand awareness) dan hipotesis ketiga $\left(\mathrm{H}_{3}\right.$ : corporate social responsibility berpengaruh positif terhadap corporate image). Hasil analisis regresi langkah 2 dapat dilihat pada tabel 2.

Tabel 2. Hasil Analisis Regresi Langkah 2

\begin{tabular}{cccc}
\hline Model & Beta & Nilai Signifikansi & Keterangan \\
\hline $\mathrm{X} \rightarrow \mathrm{M}_{1}$ & 0,597 & 0,000 & Positif dan signifikan \\
$\mathrm{X} \rightarrow \mathrm{M}_{2}$ & 0,608 & 0,000 & Positif dan signifikan \\
\hline
\end{tabular}

Sumber : Data primer diolah, 2021

Berdasarkan tabel 2 diketahui bahwa hasil analisis regresi pengaruh corporate social responsibility $(\mathrm{X})$ terhadap brand awareness $\left(\mathrm{M}_{1}\right)$ menghasilkan nilai koefisien regresi $(\mathrm{b})$ corporate social responsibility $(\mathrm{X})$ terhadap brand awareness $\left(\mathrm{M}_{1}\right)$ sebesar 0,597 dengan nilai signifikansi 0,000 ( $\left.p_{\text {value }}<0,05\right)$. Sehingga diperoleh persamaan garis regresi $\mathrm{M}_{1}=0,597 \mathrm{X}$. Hal ini menunjukkan bahwa hipotesis kedua $\left(\mathrm{H}_{2}\right)$ yang diajukan dalam penelitian yaitu corporate social responsibility berpengaruh positif terhadap brand awareness diterima.

Diterimanya hipotesis kedua $\mathrm{H}_{2}$ dalam penelitian ini karena program corporate social responsibility (CSR) berkepentingan untuk meningkatkan kesejahteraan nasabah sehingga akan membentuk kesadaran merek tentang PT Bank BRI (Persero) yang menyediakan layanan terbaik diantara Bank pesaing. PT Bank BRI (Persero) tetap konsisten dalam memberikan pelayanan kepada segmen usaha mikro, kecil dan menengah (UMKM). Dengan bekal pengalaman dan kemampuan yang matang, PT Bank BRI (Persero) mampu mempertahankan prestasinya selama 14 tahun berturut-turut dari tahun 2004 hingga saat ini, sebagai bank dengan laba terbesar di Indonesia.

Keberhasilan yang tercapai tidak terlepas dari upaya dan kerja keras PT Bank BRI (Persero) yang secara terus menerus melakukan inovasi produk dan jasa perbankan serta melaksanakan program CSR yang memiliki dampak pada kesadaran merek nasabah dalam mengingat logo dan simbol, dapat mengenali merek serta dapat membedakan PT Bank BRI (Persero) dengan bank lain. Dengan demikian, nasabah dapat mengetahui fungsi daripada program CSR yang dilakukan oleh PT Bank BRI (Persero) dalam menciptakan kesadaran merek yang kuat di benak nasabah.

Berdasarkan table 2 hasil analisis regresi pengaruh corporate social responsibility $(\mathrm{X})$ 
terhadap corporate image $\left(\mathrm{M}_{2}\right)$ menghasilkan nilai koefisien regresi (b) corporate social responsibility $(\mathrm{X})$ terhadap corporate image $\left(\mathrm{M}_{2}\right)$ sebesar 0,608 dengan nilai signifikansi 0,000 $\left(p_{\text {value }}<0,05\right)$. Sehingga diperoleh persamaan garis regresi $\mathrm{M}_{2}=0,608 \mathrm{X}$. Hal ini menunjukan bahwa hipotesis ketiga $\left(\mathrm{H}_{3}\right)$ yang diajukan dalam penelitian yaitu corporate social responsibility berpengaruh positif terhadap corporate image diterima.

Diterimanya hipotesis ketiga $\mathrm{H}_{3}$ dalam penelitian ini karena PT Bank BRI (Persero) berkomitmen menjadikan BRI Peduli sebagai kegiatan CSR yang memberikan dampak positif bagi masyarakat. Pelaksanaan program CSR secara maksimal memberikan kesan yang baik terhadap PT Bank BRI (Persero), sehingga PT Bank BRI (Persero) memiliki reputasi microbanking perusahaan yang baik di benak nasabah.

Mengakarnya persepsi masyarakat akan reputasi PT Bank BRI sebagai micro banking, mendorong PT Bank BRI (Persero) senantiasa mengembangkan layanan yang relevan atau sesuai dengan kebutuhan masyarakat Indonesia. Hal ini dapat dilihat dari upaya PT Bank BRI (Persero) dalam melaksanakan CSR dan menyelaraskan bisnisnya dengan perkembangan demografi masyarakat yang merambah ke wilayah perkotaan dan perdesaan, yang ditandai PT Bank BRI (Persero) banyak sekali ditemukan di berbagai pelosok kota, kecamatan sebagai bank cabang BRI. Hal tersebut, menambah kepercayaan nasabah akan akses layanan yang diberikan oleh PT Bank BRI (Persero) sangat membantu dan memudahkan nasabah dalam bertransaksi. Dengan demikian, berdampak pada nasabah akan memiliki citra perusahaan yang lebih baik daripada pesaingnya. Jadi, dengan adanya corporate image PT Bank BRI (Persero) yang baik dapat memotivasi nasabah untuk menggunakan produk dan jasa layanan keuangan PT Bank BRI (Persero).

\section{Langkah 3}

Langkah 3 bertujuan untuk membuktikan hipotesis keempat $\left(\mathrm{H}_{4}\right.$ : brand awareness berpengaruh positif terhadap brand equity) dan hipotesis kelima $\left(\mathrm{H}_{5}\right.$ : corporate image berpengaruh positif terhadap brand equity). Hasil analisis regresi langkah 3 dapat dilihat pada Tabel 3.

Tabel 3. Hasil Analisis Regresi Langkah 3

\begin{tabular}{cccc}
\hline Model & Beta & Nilai Signifikansi & Keterangan \\
\hline $\mathrm{M}_{1} \rightarrow \mathrm{Y}$ & 0,748 & 0,000 & Positif dan signifikan \\
$\mathrm{M}_{2} \rightarrow \mathrm{Y}$ & 0,776 & 0,000 & Positif dan signifikan \\
\hline
\end{tabular}

Sumber: Data primer diolah, 2021

Berdasarkan tabel 3 diketahui bahwa hasil analisis regresi pengaruh brand equity (Y) terhadap brand awareness $\left(\mathrm{M}_{1}\right)$ menghasilkan nilai koefisien regresi (b) brand equity (Y) 
terhadap brand awareness $\left(\mathrm{M}_{1}\right)$ sebesar 0,748 dengan nilai signifikansi 0,000 ( $\left.\mathrm{p}_{\text {value }}<0,05\right)$. Dengan demikian diperoleh persamaan garis regresi $\mathrm{M}_{1}=0,748 \mathrm{Y}$. Hal ini menunjukkan bahwa hipotesis keempat yang diajukan dalam penelitian yaitu brand equity berpengaruh positif terhadap brand awareness diterima.

Diterimanya hipotesis keempat $\mathrm{H}_{4}$ dalam penelitian ini dikarenakan masyarakat menyadari tentang produk dan layanan PT Bank BRI (Persero) sebagai penyedia layanan keuangan yang terbaik. Dengan demikian, masyarakat memilih PT Bank BRI (Persero) sebagai pilihan penyediaan layanan terbaik. Salah satu faktor yang memengaruhi kesadaran akan merek adalah mudahnya menemukan produk atau jasa layanan yang diberikan oleh perusahaan. Dapat kita ketahui bahwa PT Bank BRI (Persero) memiliki lebih dari 9.600 unit kerja yang tersebar di seluruh Indonesia. PT Bank BRI (Persero) juga dibantu oleh 467 kantor cabang, 611 Kantor Cabang Pembantu, 952 kantor kas dan 5.382 BRI Unit.

Nasabah akan mudah untuk mendapatkan informasi mengenai produk keuangan dari PT Bank BRI (Persero) karena banyaknya pusat layanan informasi yang tersedia. Nasabah akan dengan mudah untuk mengingat PT Bank BRI (Persero) apabila membutuhkan layanan keuangan karena dekat, cepat, dan mudah. Kesadaran masyarakat akan pelayanan PT Bank BRI (Persero) yang menyediakan layanan keuangan terbaik tidak terlepas dari kepuasan nasabah dalam layanan keuangan. Hal ini dapat dilihat dari eksistensi PT Bank BRI (Persero) dalam dunia perbankkan di Indonesia.

Bank BRI berdiri sejak tahun 1985 dan berdasarkan Peraturan Pemerintah Nomor 1 Tahun 1946 Pasal 1 yang menegaskan PT Bank BRI (Persero) menjadi bank milik pemerintah. Kini, BRI menjadi salah satu terbesar milik pemerintah, bahkan jumlah nasabahnya pun tercatat yang paling banyak di antara bank pesaing lainnya. Dapat disimpulkan bahwa keberhasilan memiliki nasabah terbanyak mencerminkan kualitas layanan keuangan terbaik yang diberikan oleh PT Bank BRI (Persero) akan menambah nilai brand equity dengan kesadaran merek nasabah untuk menggunakan jasa keuangan PT Bank BRI (Persero) daripada bank pesaing lainnya.

Berdasarkan tabel 3 diketahui bahwa berdasarkan analisis regresi pengaruh brand equity $(\mathrm{Y})$ terhadap corporate image $\left(\mathrm{M}_{2}\right)$ menghasilkan nilai koefisien regresi (b) brand equity $(\mathrm{Y})$ terhadap corporate image $\left(\mathrm{M}_{2}\right)$ sebesar 0,776 dengan nilai signifikansi $0,000\left(\mathrm{p}_{\text {value }}<0,05\right)$. Dengan begitu, diperoleh persamaan garis regresi $\mathrm{M}_{1}=0,776 \mathrm{Y}$. Hal ini menunjukkan bahwa hipotesis kelima yang diajukan dalam penelitian yaitu brand equity berpengaruh positif terhadap corporate image diterima.

Diterimanya hipotesis kelima $\mathrm{H}_{5}$ dalam penelitian ini dikarenakan citra perusahaan PT 
Bank BRI (Persero) di mata masyarakat memiliki kesan yang baik sehingga masyarakat memilih menggunakan jasa layanan PT Bank BRI (Persero) daripada bank pesaing lainnya. PT Bank BRI (Persero) mempunyai identitas yang sangat mudah diingat yaitu warna biru. Dilihat dari kepanjangan Bank Rakyat Indonesia yang secara tidak langsung mengartikan bank milik rakyat Indonesia. Dalam Best Banking Brand Award 2017 PT Bank BRI (Persero) mendapat peringkat dua dalam kategori Good Financial Performance, Category: State-owned Bank. Hal ini menunjukkan bahwa PT Bank BRI (Persero) mempunyai citra yang bagus di mata masyarakat karena menduduki bank pertama pilihan masyarakat.

Corporate image yang terbentuk di masyarakat akan menguntungkan PT Bank BRI (Persero) karena menjadi pilihan masyarakat secara psikologis karena mendapat penilaian memiliki citra yang baik. Corporate image memiliki kaitan yang sangat erat dengan brand equity, di mana brand equity akan terbentuk dengan baik dengan adanya corporate image. Membuat citra kepada masyarakat bukan merupakan hal yang mudah untuk dicapai, perlu adanya pelayanan maksimal dalam melayani konsumen dalam layanan keuangan. Kesan yang baik dari konsumen dalam hal ini merupakan hasil kerja keras selama bertahun dalam pelayanan keuangan yang dicapai untuk menjadi bank terbaik yang menjadi pilihan masyarakat. Citra yang baik di benak masyarakat dapat terbentuk karena adanya kepercayaan mengenai kualitas layanan yang diberikan, sehingga nasabah tidak akan berpaling ke bank lain karena sudah memiliki ikatan emosional yang membuat konsumen memilih menggunakan layanan menguntungkan PT Bank BRI (Persero) karena citranya yang baik daripada bank pesaing lainnya.

\section{Langkah 4}

Langkah 4 bertujuan untuk membuktikan hipotesis keenam $\left(\mathrm{H}_{6}\right.$ : corporate social responsibility berpengaruh positif terhadap brand equity dengan brand awareness sebagai variabel mediasi) dan hipotesis ketujuh $\left(\mathrm{H}_{7}\right.$ : corporate social responsibility berpengaruh positif terhadap brand equity dengan corporate image sebagai variabel mediasi). Hasil perbandingan langkah 4 dapat dilihat pada tabel 4.

Tabel 4. Hasil Analisis Regresi langkah 4

\begin{tabular}{cccc}
\hline Model & Beta & Nilai Signifikansi & Keterangan \\
\hline$X \rightarrow Y$ & 0,241 & 0,001 & Positif dan signifikan \\
$X+M_{1} \rightarrow Y$ & 0,604 & 0,000 & Partially Mediated \\
$X \rightarrow Y$ & 0,206 & 0,004 & Positif dan signifikan \\
$X+\mathrm{M}_{2} \rightarrow Y$ & 0,651 & 0,000 & Partially Mediated \\
\hline
\end{tabular}

Sumber : Data primer diolah, 2021

Berdasarkan tabel 4 tersebut diketahui bahwa hasil analisis regresi pengaruh corporate 
social responsibility $(\mathrm{X})$ terhadap brand equity $(\mathrm{Y})$ tanpa memasukkan brand awareness $\left(\mathrm{M}_{1}\right)$ menghasilkan nilai signifikansi 0,001 $\left(p_{\text {value }}<0,05\right)$. Setelah dilakukan analisis dengan memasukan brand awareness $\left(\mathrm{M}_{1}\right)$ pada analisis regresi antara corporate social responsibility (X) terhadap brand equity (Y) menghasilkan peningkatan dengan nilai signifikansi sebesar 0,000 ( $p$ value $<0,05)$. Hal ini membuktikan bahwa hipotesis keenam $\left(\mathrm{H}_{6}\right)$ yaitu corporate social responsibility berpengaruh positif dan signifikan terhadap brand equity dengan brand awareness sebagai variabel mediasi, dalam hal ini berupa partially mediated dapat diterima.

Hal tersebut bermakna bahwa CSR yang dilakukan dengan baik oleh PT Bank BRI (Persero) akan berpengaruh terhadap kesadaran merek nasabah yang dapat meningkatkan brand equity PT Bank BRI (Persero). Program CSR yang diberi nama BRI Peduli menjadi strategi pemasaran dan dikelola dengan baik bertanggung jawab sosial dan lingkungan yang dapat membentuk kesadaran merek tentang PT Bank BRI (Persero). Dengan melaksanakan program CSR secara continue memudahkan nasabah dalam mengenali produk dan jasa keuangan serta mengingat logo/ simbol PT Bank BRI (Persero).

PT Bank BRI telah melakukan pengendalian dan pengembangan produk, program pemasaran, dan komunikasi pemasaran yang berorientasi untuk menjaga, meningkatkan brand awareness dan membangun ekuitas merek. Beberapa produk dari PT Bank BRI diantaranya adalah Untung Beliung BRItama, program produk e-channel, parade UMKM, program pembelian pulsa/listrik via mobile banking, program transaksi e-Pay berhadiah. Dengan kekuatan program yang dimiliki PT Bank BRI (Persero) maka nasabah dapat membedakan dan lebih memilih PT Bank BRI (Persero) dibandingkan dengan bank pesaing lainnya yang memiliki kesamaan dalam pelayanan. Hal ini membuktikan bahwa semua program yang dijalankan oleh PT Bank BRI (Persero) dapat menambah nilai dari brand equity, seperti persepsi kualitas produk dan jasa keuangan yang ditawarkan, peningkatan awareness, pengalaman, sekaligus loyalitas nasabah karena dapat dirasakan nasabah di seluruh Indonesia.

Tabel 4 juga menunjukkan hasil analisis regresi pengaruh corporate social responsibility (X) terhadap brand equity $(\mathrm{Y})$ tanpa memasukkan corporate image $\left(\mathrm{M}_{2}\right)$ menghasilkan nilai signifikansi 0,004 ( $\left.p_{\text {value }}<0,05\right)$. Setelah dilakukan analisis dengan memasukan corporate image $\left(\mathrm{M}_{2}\right)$ pada analisis regresi antara corporate social responsibility $(\mathrm{X})$ terhadap brand equity $(\mathrm{Y})$, dengan menghasilkan peningkatan nilai signifikansi sebesar $0,000\left(p_{\text {value }}<0,05\right)$. Hal ini membuktikan bahwa hipotesis ketujuh $\left(\mathrm{H}_{7}\right)$ yaitu corporate social responsibility berpengaruh positif dan signifikan terhadap brand equity dengan corporate image sebagai variabel mediasi, dalam hal ini berupa partially mediated dapat diterima. Berdasarkan hasil penelitian dapat disimpulkan bahwa dengan melaksanakan program-program CSR secara 
continue dapat membangun corporate image yang baik di benak nasabah.

Melalui program CSR dapat meningkatkan brand equity perusahaan. Bank yang memiliki brand equity yang kuat akan tetap mampu bersaing menguasai pasar. Semakin kuat brand equity sebuah bank, semakin kuat pula daya tariknya di mata nasabah. Salah satu upaya yang dilakukan PT Bank BRI (Persero) untuk menguasai pasar yakni dengan melakukan program Bina Lingkungan yang diberi nama BRI Peduli. BRI Peduli merupakan suatu alat atau mekanisme tanggung jawab sosial perusahaan yang digunakan PT Bank BRI (Persero) dengan tujuan untuk meningkatkan brand equity melalui penawaran pengalaman jasa layanan keuangan. Meningkatnya brand equity perusahaan, membuat citra perusahaan PT Bank BRI (persero) menjadi lebih baik dan berkesan di benak masyarakat. Dengan demikian dapat ditarik kesimpulan bahwa CSR dapat menjadi pengaruh corporate image terhadap meningkatnya brand equity PT Bank BRI (Persero).

\section{E. KESIMPULAN}

Penelitian ini diharapkan dapat memberikan masukan informasi dan dijadikan bahan pertimbangan bagi PT Bank BRI (Persero) dalam menentukan langkah yang diambil di masa yang akan datang yang berorientasi terhadap brand equity PT Bank BRI (Persero). Sebaiknya PT Bank BRI (Persero) mempertahankan program CSR yang dikelola dengan baik untuk mencapai networking calon nasabah PT Bank BRI (Persero). Secara nyata PT Bank BRI (Persero) telah berhasil melaksanakan program CSR yang bertanggung jawab sosial yang dikenal dengan nama BRI Peduli. PT Bank BRI (Persero) berkomitmen menjadikan BRI Peduli sebagai kegiatan yang memberikan dampak positif bagi masyarakat terbagi dalam 7 (tujuh) sektor bantuan. Dengan pelaksanaan program CSR tersebut mampu berpengaruh terhadap kesadaran nasabah dalam memilih jasa layanan keuangan yang ditawarkan oleh PT Bank BRI (Persero) sebagai lembaga jasa keuangan terbesar di Indonesia yang memiliki usia 125 tahun. Di usia tersebut PT Bank BRI (Persero) membuat persepsi di benak nasabah sebagai perusahaan dengan merek (brand) yang baik, peduli terhadap lingkungan sosial masyarakat dengan program CSR yang dilakukan oleh PT Bank BRI (Persero). Hal ini dapat menjadi kunci untuk memenangkan persaingan di dunia perbankan dalam jangka panjang dan mempertahankan daya tarik nasabah. Dengan adanya CSR yang baik mampu meningkatkan brand awareness pada diri nasabah yang pada akhirnya dapat menambah nilai brand equity PT Bank BRI (Persero).

PT Bank BRI (Persero) harus meningkatkan pelaksanaan program CSR agar dapat menciptakan corporate image menjadi baik di benak nasabah dengan cara berperan aktif di 
dalam 7 (tujuh) sektor bantuan pelaksanaan program CSR tersebut untuk meningkatkan corporate image berdampak pada citra positif yang berkesinambungan bagi seluruh jasa layanan keuangan yang dihasilkan oleh PT Bank BRI (Persero). Hal ini dapat menjadi kunci dalam memenangkan persaingan di dunia perbankan dalam jangka panjang dan mempertahankan daya tarik nasabah. Sehingga, dengan adanya CSR yang baik diharapkan corporate image pada diri nasabah akan terus meningkat yang pada akhirnya dapat menambah nilai brand equity PT Bank BRI (Persero).

Terbuktinya hipotesis - hipotesis pada penelitian ini, sejalan dengan pendapat Hoeffler \& Keller (2002), Aaker (1991), Kotler (2008), Keller (2013), Huang \& Sarigollu (2011), dan Jones (2005). Selain itu penelitian ini menambah referensi pada bidang pemasaran, khususnya yang berkaitan dengan pengaruh corporate social responsibility terhadap brand equity dengan brand awareness dan corporate image sebagai variabel mediasi. Penelitian ini sesuai dan/atau menguatkan hasil penelitian sebelumnya yang dilakukan oleh Hafez (2018), Lai et al. (2010), Fatma et al. (2015), Bankas (2010), Kim \& Hyun (2011), dan Singh \& Verma (2017).

Penelitian yang telah dilakukan masih terdapat keterbatasan. Hal ini dikarenakan penelitian ini menggunakan hierarchical regression analysis dengan sampel yang digunakan hanya 120 responden. Untuk agenda penelitian mendatang, penelitian dapat dilakukan dengan objek berbeda, misalnya Bank BNI, Bank BTN, Bank Mandiri dan bank lainnya yang menerapkan corporate social responsibility dalam melakukan strategi pemasaran, sehingga diharapkan dapat lebih memaksimalkan hasil penelitian. Selain itu, penelitian selanjutnya sebaiknya mengembangkan metode pengumpulan data dengan cara lainnya, misalnya dengan metode wawancara atau lainnya agar pengumpulan data lebih efektif dan akurat. Dikarenakan dalam penelitian ini menggunakan penelitian survey dengan membagikan kuesioner pada responden, terkadang responden kurang paham dengan pernyataan yang ada pada kuesioner sehingga membuat peneliti harus menjelaskan maksud dari pernyataan tersebut. Oleh karena itu, dengan melakukan wawancara diharapkan dapat lebih memudahkan peneliti untuk mendapatkan data yang lebih lengkap.

\section{DAFTAR PUSTAKA}

Aaker, David.A. (1991). Managing Brand Equity. New York: The Free Press.

Abratt, R. \& Kleyn, N. (2012). Corporate Identity, Corporate Branding and Corporate Reputations: Reconciliation and Integration. European Journal of Marketing, 46 (Nos 7/8), 1048-1063. 
Alhaddad, A.A. (2015). The Effect of Advertising Awareness On Brand Equity In Social Media. International Journal of e-Education, e-Business, e-Management and eLearning, 5(2), 73-84.

Arendt, S. \& Brettel, M. (2010). Understanding the Influence Of Corporate Social Responsibility on Corporate Identity, Image, and Firm Performance. Management Decision, 48(10), 1469-1492.

Bank Rakyat Indonesia. (n.d). BRI Peduli Tentang Kami. https://bri.co.id/tentang-bri-peduli

Bankas, M.A. (2001). Corporate Social Responsibility, a Tool in Creating Corporate Brand Awareness: A Case Study Of The Telecommunication Industry In Ghana.

[Dissertation]. Berekuso: Department of Business Administration Ashesi University College.

Baron, R.M. \& Kenny, D.A. (1986). The Moderator- Mediator Variable Distinction in Social Psychological Research: Conceptual, Strategic and Statistical Considerations. Journal of Personality and Social Psychology, 51(6), 1173-1182.

Berens, G., Cees, B.M.V.R \& Garrit H.V.B., (2005). Corporate Associations and Consumer Product Responses: The Moderating Role of Corporate Brand Dominance. Journal of Marketing, 69(3).

Bhattacharya, C.B. \& Sen, S. (2004). Doing Better at Doing Good: When, Why, and How Consumers Respond to Corporate Social Initiatives. California Management Review, 47(1), 9-24.

Bhattacharya, C.B., Sen, S. \& Korschun, D. (2007). Corporate Social Responsibility as an Internal Marketing Strategy. Sloan Management Review, 49(1), 1-29.

Brown, T. J. \& Dacin, P.A. (1997). The Company and the Product: Corporate Association and Consumer Product Response. Journal of Marketing, 61(1), 68-84.

Branco, M.C. \& Rodrigues, L.L. (2006). Corporate Social Responsibility and ResourceBased Perspectives. Journal of Business Ethics, 69(2), 111-132.

Carroll, A.B. (1999). Corporate Social Responsibility: Evolution of a Definitional Construct. Business and Society, 38(3), 268-295.

Durianto, D., Sugiarto, \& Sitinjak, T. (2001). Strategi Menaklukkan Pasar Melalui Riset Ekuitas dan Perilaku Merek. Jakarta: PT Gramedia Pustaka Utama.

Fatma, M., Rahman, Z. \& Khan, I. (2015). Building Company Reputation And Brand Equity Through CSR: The Mediating Role of Trust. International Journal of Bank Marketing, 33(6), 840-856.

Fombrun, C., \& M. Shanley. (1990). What's in a Name? Reputation Building and Corporate Strategy. Academy of management journal, 33(2), 233 - 258.

Fombrun, C.J. (2005). Building Corporate Reputation Through CSR Initiatives: Evolving Standards. Corporate Reputation Review, 8(1), 7-11.

Hafez. (2018). Measuring the Impact Of Corporate Social Responsibility Practices on Brand Equity in The Banking Industry in Bangladesh: The Mediating Effect of Corporate Image and Brand Awareness. International Journal of Bank Marketing, 36(5), 806822. 
Handayani, E.N. (2012). Analisis Program Corporate Social Responsibility (CSR) dalam Membangun Corporate Reputation, Brand Equity, dan Social Equity Brand Studi Kasus pada Merek Lifebuoy dari PT Unilever. Tesis program studi Magister Manajemen pada Fakultas Ekonomi Universitas Indonesia, Jakarta.

Hartono, Jogiyanto. (2013). Metodologi Penelitian Bisnis. Yogyakarta: BPFE.

Hoeffler, S. \& Keller, K.L. (2002). Building Brand Equity Through Corporate Societal Marketing. Journal of Public Policy and Marketing, 21(1), 78-89.

Hsu, K.T. (2012). The Advertising Effects Of Corporate Social Responsibility on Corporate Reputation and Brand Equity: Evidence From The Life Insurance Industry in Taiwan. Journal of Business Ethics, 109(2), 189-201.

Hur, W.M., Kim, H., \& Woo, J. (2013). How CSR Leads to Corporate Brand Equity: Mediating Mechanisms of Corporate Brand Credibility And Reputation. Journal of Business Ethics, 12(1), 75-86.

Jalleh, Geoffrey, \& Donovan, R.J. (2002). Sponsorship: Impact on Brand on Brand awareness and Brand attitudes. SMQ, 7(1).

Jefkins, Frank, (1996). Essential of A Public Relations. Heinemann Asia Singapore.

Jones, T. M. (1980). Corporate Social Responsibility Revisited, Redefined. California Management Review, 22(3), 59-67.

Jones, B., R. (2005). Finding Sources of Brand Value: Developing a Stakeholder Model of Brand Equity. Journal of Brand Management, 13(1), 10-32.

Kasali, R. (2007). Membidik Pasar Indonesia: Segmentasi, Targeting, dan Positioning. Jakarta: Gramedia Pustaka Utama.

Keller, K.L. (1993). Conceptualizing, measuring, and managing customer-based brand equity. Journal of Marketing,57(1), 1-22.

Keller, K.L. (2013). Strategic Brand Management: Building, Measuring and Managing Brand Equity (2 ed.). New Jersey: Prentice-Hall.

Kotler, Philip \& Lee, Nancy. (2005). Corporate Social Responsibility; Doing the Most Good you're your Company and Your Cause. NewJersey: JohnWiley \& Sons, Inc

Kotler, Philip. (2008). Marketing Management (10th ed). New Delhi: Prentice Hall.

Klein, J. and Dawar, N. (2004). Corporate Social Responsibility and Consumers' Attributions And Brand Evaluations in a Product-Harm Crisis. International Journal of Research in Marketing, 21(3), 203-217.

Kim, J.H. \& Hyun, Y. (2011). A Model to Investigate the Influence of Marketing- Mix Efforts and Corporate Image on Brand Equity in the IT Software Sector. Industrial Marketing Management, 40(3), 424-438.

Kuncoro, Mudrajad. (2013). Metode Riset untuk Bisnis \& Ekonomi (4 ed.). Jakarta: Erlangga.

Lai, C.S., Chiu, C.J., Yang, C.F. \& Pai, D.C. (2010). The Effects of Corporate Social Responsibility On Brand Performance: The Mediating Effect of Industrial Brand Equity and Corporate Reputation. Journal of Business Ethics, 95(3), 457-469. 
Lantos, G.P. (2001). The Boundaries of Strategic Corporate Social Responsibility. Journal of Consumer Marketing, 18(7), 595-632.

Luo, X. \& Bhattacharya, C.B. (2006). Corporate Social Responsibility, Customer Satisfaction, and Market Value. Journal of Marketing, 70(4), 1-18.

Macdonald, E \& Sharp, B. (2003). Management Perceptions of the Importance of Brand Awareness as an Indication of Advertising Effectiveness. Marketing Bulletin, 14(2), $1-15$.

McWilliams, A., Siegel, D.S. \& Wright, P.M. (2006). Corporate Social Responsibility: Strategic Implications, Journal of Management Studies, 43(1), 1-18.

Mitra, R. (2011). Framing the Corporate Responsibility-Reputation Linkage: The Case of Tata Motors In India, Public Relations Review, 37(4), 392-398.

Netemeyer et.al (2004) Developing and Validationg Measures of Facets of Customer-Based Brand Equity. Journal of Business Research, 57, 209 -224.

Nguyen, N \& Leblanc, G. (2001). Corporate Image and Corporate Reputation in Customer Retention Decisions in Service. Journal of Retailing and Consumer Services, $8(4), 227-236$.

Pouromid, B. \& Iranzadeh, S. (2012). The evaluation of the factors affects on the brand equity of Pars Khazar household appliances based on the vision of female consumer. Middle-East Journal of Scientific Research, 12(8), 1050-1055.

Roberts, P. W., \& Dowling, G. R. (2002). Corporate Reputation and Sustained Superior Financial Performance. Strategic Management Journal, 23(12), 1077-1093.

Sen, S. \& Bhattacharya, C.B. (2001) Does Doing Good Always Lead to Doing Better? Consumer Reactions to Corporate Social Responsibility. Journal of Marketing Research, 38(2), 25-243.

Shimp, A.T. (2014). Komunikasi Pemasaran Terpadu dalam Periklanan dan Promosi. Jakarta: Salemba Empat.

Singh, A. \& Verma, P. (2017). How CSR Affects Brand Equity of Indian Firms?, Global Business Review, 18(3), 1-18.

Smith, Paul. R \& Taylor, J. (2004). Marketing Communications. An integrated approach. London and Philadelphia: Kogan Page.

Sofyani, S, \& Hurriyati, R. (2010). Pengaruh Corporate Social Responsibility Terhadap Corporate Image PT Bank Negara Indonesia, Tbk. Strategic, 9(8), 66-67.

Vazifehdust, H., Mojoudi, A. \& Jalalian, S. (2014). The Effect of Corporate Social Responsibility on Corporate Image, Customer Satisfaction and Loyalty in The Banking Industry (Case Study: Tehran Melli Bank). Conference of Development and Innovation Management in Management Empowerment, 1-23.

Wang, H.D. (2010). Corporate Social Performance and Financial-Based Brand Equity. Journal of Product and Brand Management, 19 (5), 335-345.

Wilcox, J.B., Laverie, D.A., Kolyesnikova, N., Duhan, D.F. \& Dodd, T.H. (2008), Facets of Brand equity and Brand survival: a longitudinal examination, International Journal of Wine Business Research, 20(3), 202-214. 
Yoo, B., Donthu, N. \& Lee, S. (2000). An Examination of Selected Marketing Mix Elements and Brand Equity. Journal of the Academy of Marketing Science, 28, 195-211.

Yoo, B. \& Donthu, N. (2001). Developing and Validating a Multidimensional Consumer Based Brand Equity Scale, Journal of Business Research, 52(1), 1-14.

Yoon, Y., Gurhan-Canli, Z. \& Schwarz, N. (2006). The Effect of Corporate Social Responsibility (CSR) Activities on Companies with Bad Reputations. Journal of Consumer Psychology, 16 (4), 377-390. 